\title{
The Vasoreparative Potential of Endothelial Colony Forming Cells: A Journey Through Pre-clinical Studies
}

\author{
Christina L. O’Neill, Kiran J. McLoughlin, Sarah E. J. Chambers, Jasenka Guduric-Fuchs, \\ Alan W. Stitt and Reinhold J. Medina*
}

Centre for Experimental Medicine, Queen's University Belfast, Belfast, United Kingdom

OPEN ACCESS

Edited by:

Ulrich Martin,

Hannover Medical School, Germany

Reviewed by:

Marian Klinger,

Wroclaw Medical University, Poland Marco Diego Dominietto, Universität Basel, Switzerland

*Correspondence: Reinhold J. Medina r.medina@qub.ac.uk

Specialty section: This article was submitted to

Translational Medicine, a section of the journal

Frontiers in Medicine

Received: 29 June 2018 Accepted: 05 September 2018

Published: 16 October 2018

Citation:

O'Neill CL, McLoughlin KJ, Chambers SEJ, Guduric-Fuchs J,

Stitt AW and Medina RJ (2018) The Vasoreparative Potential of Endothelial

Colony Forming Cells: A Journey

Through Pre-clinical Studies.

Front. Med. 5:273

doi: 10.3389/fmed.2018.00273
For over a decade various cell populations have been investigated for their vasoreparative potential. Cells with the capacity to promote blood vessel regeneration are commonly known as endothelial progenitor cells (EPCs); although such a definition is currently considered too simple for the complexity of cell populations involved in the reparative angiogenic process. A subset of EPCs called endothelial colony forming cells (ECFCs) have emerged as a suitable candidate for cytotherapy, primarily due to their clonogenic progenitor characteristics, unequivocal endothelial phenotype, and inherent ability to promote vasculogenesis. ECFCs can be readily isolated from human peripheral and cord blood, expanded ex vivo and used to revascularize ischemic tissues. These cells have demonstrated efficacy in several in vivo preclinical models such as the ischemic heart, retina, brain, limb, lung and kidney. This review will summarize the current pre-clinical evidence for ECFC cytotherapy and discuss their potential for clinical application.

Keywords: endothelial progenitor cells (EPC), angiogenesis, cell therapy, endothelial colony forming cells (ECFCs), ischemia, vascular repair

\section{THE POTENTIAL OF VASCULAR REGENERATION AS A THERAPEUTIC GOAL}

Vasodegeneration and the ensuing tissue ischemia remains a significant challenge for healthcare systems worldwide. Diseases such as ischemic heart disease, stroke, peripheral artery disease, and ischemic retinopathies are complex to treat because there are diverse underpinning causes of nonperfusion and each tissue exhibits a distinct response to hypoxia. Current available treatments aim to remove damaged tissue, widen obstructed blood vessels or replace blocked vasculature with bypass surgery. A potential new approach would be to regenerate the compromised vasculature using so-called "therapeutic angiogenesis". While delivery of pro-angiogenic peptides have often provided scope for achieving re-perfusion, the use of cell therapy products have gained favor since they can offer sustained delivery of a multitude of angiogenic factors and/or provide direct replacement of damaged vascular cells (1). Although several cell-types such as mesenchymal stem cells (MSCs) (2), embryonic stem cells (ESCs) (3), and induced pluripotent stem cells (iPSCs) (4) have been tested pre-clinically for their therapeutic potential, endothelial progenitor cells (EPCs) have emerged as a population of cells with promising tissue regenerative properties.

EPCs have been the subject of considerable controversy due to their ambiguous definition (5) and this term actually encompasses a range of very different cell types (6). Cells named as myeloid angiogenic cells (MACs), circulating angiogenic cells (CACs), and early EPCs, all of which are hematopoietic cells, have been shown to promote vascular repair through paracrine mechanisms. 
Recently, leading experts in the field published a consensus statement on EPC nomenclature to standardize terminology (7). Endothelial progenitors are thus defined as cells with an unequivocal endothelial phenotype, self-renewal potential and a capacity for de novo, in vivo blood vessel formation. It is now widely accepted that endothelial colony forming cells (ECFCs) comply with this definition and are considered the "bona fide endothelial progenitor" with emerging therapeutic potential (7).

\section{WHAT ARE ECFCS?}

Endothelial colony forming cells (ECFCs) are sometimes referred to in the literature as late Endothelial Progenitor cells (due to their later appearance in culture), blood outgrowth endothelial cells, or outgrowth endothelial cells. ECFCs are isolated in vitro from the cultured mononuclear fraction of peripheral blood or umbilical cord blood, grown under endothelial conditions. They appear in culture as cobblestone shaped colonies within weeks of mononuclear cell plating and have significant proliferative potential (Figure 1) (8). It has been demonstrated that ECFCs can also be derived from human induced pluripotent stem cells by sorting for markers Neuropilin-1 and CD31 (9). In addition to cord blood, ECFCs have also been successfully isolated from fat tissue (10), placenta (11), and lungs (12); these findings suggest that ECFCs originate from tissue resident vascular progenitors. Recent reports pinpoint specific endothelial subsets within the vasculature and these may constitute "vascular stem cells" with homeostatic reparative roles. These vascular stem cells are identified by the expression of CD201, the protein $C$ receptor (PROCR) EPCR, a type 1 transmembrane receptor which is known to be highly expressed on vascular endothelial stem cells (VESCs). PROCR + selection facilitates their isolation and enriches for highly clonogenic cells with bipotent differentiation capacity into endothelial cells and pericytes (13). CD157, also known as bone marrow stromal antigen 1 has also been identified as a marker of tissue resident VESCs, it is expressed in endothelial cells of large vessels and CD157+ cells possess significant vascular regenerative potential (14).

\section{THE HALLMARKS OF ECFCS}

ECFCs typically exhibit high clonogenic capacity. Indeed, these cells can yield a hierarchy of different sized colonies with umbilical cord blood giving rise to the highest frequency of largest colonies that have high proliferative potential (HPP) when compared to adult peripheral blood (15). ECFCs are characterized by the expression of endothelial markers CD31, CD146, VEGFR2, vWF, and VE-cadherin. ECFCs also express CD34, although the frequency of this marker is variable and can diminish as the cells are expanded in vitro. Importantly, ECFCs are negative for hematopoietic markers CD14 and CD45. An essential property of ECFCs is their ability to form either a de novo vascular network in vitro while in vivo these cells integrate seamlessly with the host vasculature (Figure 1).

\section{PRE-CLINICAL APPLICATION OF ECFCS}

\section{The Ischemic Retina}

Ischemic retinopathies such as retinal vein occlusion, diabetic retinopathy, and retinopathy of prematurity are common causes of visual impairment and are characterized by vasodegeneration (16). Pre-clinical evidence shows that ECFC cell therapy may be a potential treatment strategy for such ischemic retinopathies (17). The retina differs from other organs, as it has a certain degree of immune privilege and so provides a unique environment to examine the effects of human ECFCs. When these cells were injected into murine models of retinal ischemia, they promoted vascular repair, decreased the avascular area, enhanced the normovascular area, and importantly, decreased pathological neovascular tuft formation. Furthermore, human ECFCs could be found directly integrating and forming new vessels within the host murine vasculature (8). The same effects were seen when ECFCs derived from induced pluripotent stem cells were used (9). In addition, beneficial effects of ECFCs may be enhanced using agents that alter growth factor signaling pathways. For example, AAV2.COMP-Ang1 was shown to enhance the therapeutic benefit of intravitreally delivered ECFCs by promoting their integration into the murine vasculature (18). Although there is a lot more work needed before translation of ECFCs into therapy for the ischemic retina, we have recently evaluated the effect of ECFCs in the mouse oxygeninduced retinopathy model, by examining dose, delivery route, and immunogenicity. Human ECFCs delivered to the murine ischemic retina demonstrated a vasoreparative effect both by intravitreal and intracarotid delivery. Importantly, cells conferred therapeutic benefit by promoting vascular repair. In addition, if ECFCs were delivered into healthy adult mice, they were completely cleared from the retina within 3 days (17). It has also been reported that ECFCs promote vascular repair in the ischemic retina through release of paracrine factors. A subset of ECFCs was found to be effective in rescuing retinal degeneration, this subset was found to express high levels of CD44, the hyaluronic acid receptor (19). Taken together, these data provide convincing scientific evidence to support ECFCs as a potential cell therapy for ischemic retinopathies.

\section{The Ischemic Brain}

Ischemic stroke is a common worldwide cause of mortality. Fewer than $10 \%$ of patients experiencing ischemic stroke are suitable for thrombolysis treatment which can effectively restore some cerebral blood flow (20), therefore there is a need for therapies that induce vascular repair and more effectively restore blood flow for greater number of patients. ECFCs are emerging as a promising new treatment option for ischemic stroke and their therapeutic potential in the rodent brain has been demonstrated. For example, GFP-labeled ECFCs were tracked for cell engraftment in a photothrombotic ischemic stroke mouse model. Cells were delivered via the left cardiac ventricle $24 \mathrm{~h}$ after stroke. Bioluminescence signals were highest in the brain on day 1 and decreased steadily until day 14. GFP-positive ECFCs were found at the infarct border demonstrating a successful homing response to regions of tissue hypoxia. Importantly, 

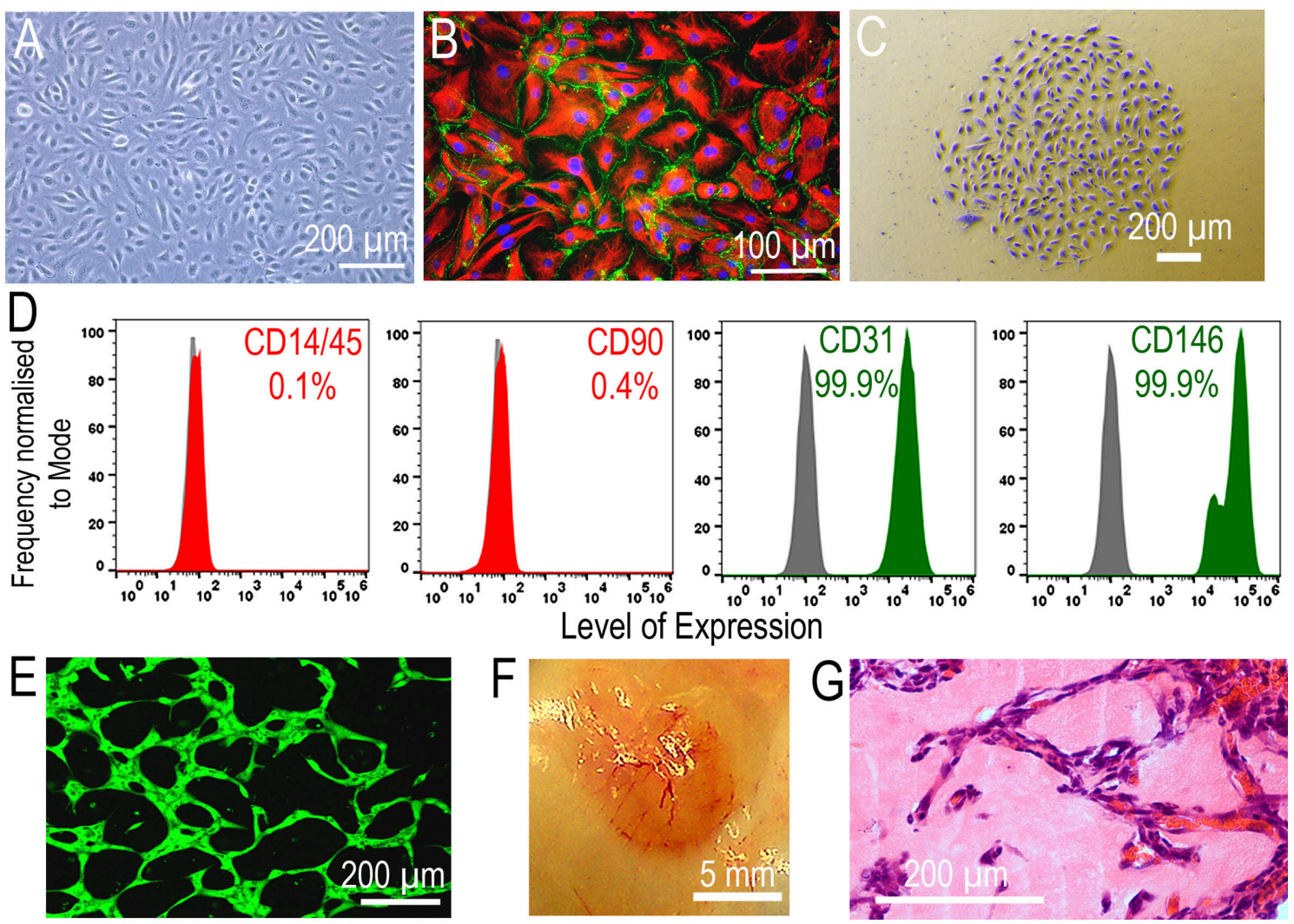

FIGURE 1 | Properties of ECFCs. (A) ECFC cobblestone monolayer morphology (Scale bar $200 \mu \mathrm{m}$ ). (B) A tight monolayer of ECFCs with adherens junctions ( $\beta$ catenin $=$ green, Vimentin $=$ red, scale bar $100 \mu \mathrm{m}$ ). (C) A colony derived from a single cell demonstrating clonogenic potential of ECFCs (crystal violet stained, scale bar $200 \mu \mathrm{m}$ ). (D) ECFCs express endothelial markers CD31 \& CD146 and are negative for hematopoietic markers CD14/45 and stromal marker CD90. (E) ECFCs have tubulogenic capacity in vitro (scale bar $200 \mu \mathrm{m}$ ) (F,G). ECFCs form perfused vessels in vivo in the Matrigel plug assay (Scale bar, $5 \mathrm{~mm}$ and $200 \mu \mathrm{m}$ respectively).

ECFC therapy led to improved angiogenesis, neurogenesis, decreased neuronal apoptosis, and ultimately led to restoration of brain function (21). In addition, in a rat model of transient focal cerebral ischemia and middle cerebral artery occlusion (MCAO), ECFCs primed with erythropoietin (EPO) were shown to have enhanced efficacy for reversing stroke injury $(22,23)$. In another study using the same model, labeled ECFCs administered intravenously $24 \mathrm{~h}$ after MCAO were seen to specifically home to the ischemic hemisphere and settled in the injured area. ECFCs transplantation stimulated an increase in capillary density at the site of injury. Although in this study, ECFCs were not detected integrating within the vasculature, they stimulated an increase in proangiogenic growth factor expression at the ischemic site, which was also associated with a reduction in the number of apoptotic cells (24).

ECFCs have also been examined for their potential to repair vascular damage in pre-clinical models of traumatic brain injury (TBI) in rodents. TBI, created by lateral fluid percussion injury was used to assess the effects of cord blood-derived ECFCs. Cells were intravenously infused $1 \mathrm{~h}$ after injury. ECFCs successfully homed to the injured site, were detected in the injured brain after $24 \mathrm{~h}$ and were effective in promoting neovascularization and improving neurological function (25). A further follow-up study demonstrated that infusion of ECFCs can repair blood brain barrier tight junction functionality (26). In addition, in a rat model of cerebral aneurysm, ECFC transfusion was shown to inhibit inflammatory signaling, protect smooth muscle cells from apoptosis and promote vascular regeneration (27). Taken together, these studies highlight the potential therapeutic effects of ECFCs for vascular repair in the brain.

\section{Peripheral Artery Disease}

Peripheral artery disease (PAD) can lead to ischemic injury and amputation. Prognosis is poor and current treatments for PAD patients are limited (50); therefore there is a pressing need for new strategies to enhance angiogenesis and collateral arterial growth. The potential for ECFC treatment in PAD has been demonstrated in several preclinical studies using the murine hindlimb ischemia model. Firstly, ECFCs were shown to increase perfusion by rapidly relocating to the ischemic hind limb within $6 \mathrm{~h}$ after injection. In addition, there was enhanced benefit when a combination of ECFCs and mesenchymal stem cells (MSCs) were used. Further analysis showed that the reparative effects of ECFC therapy were due to direct vascular incorporation (28). Although it has also been suggested that ECFCs can function as paracrine mediators, modulating MSC engraftment 


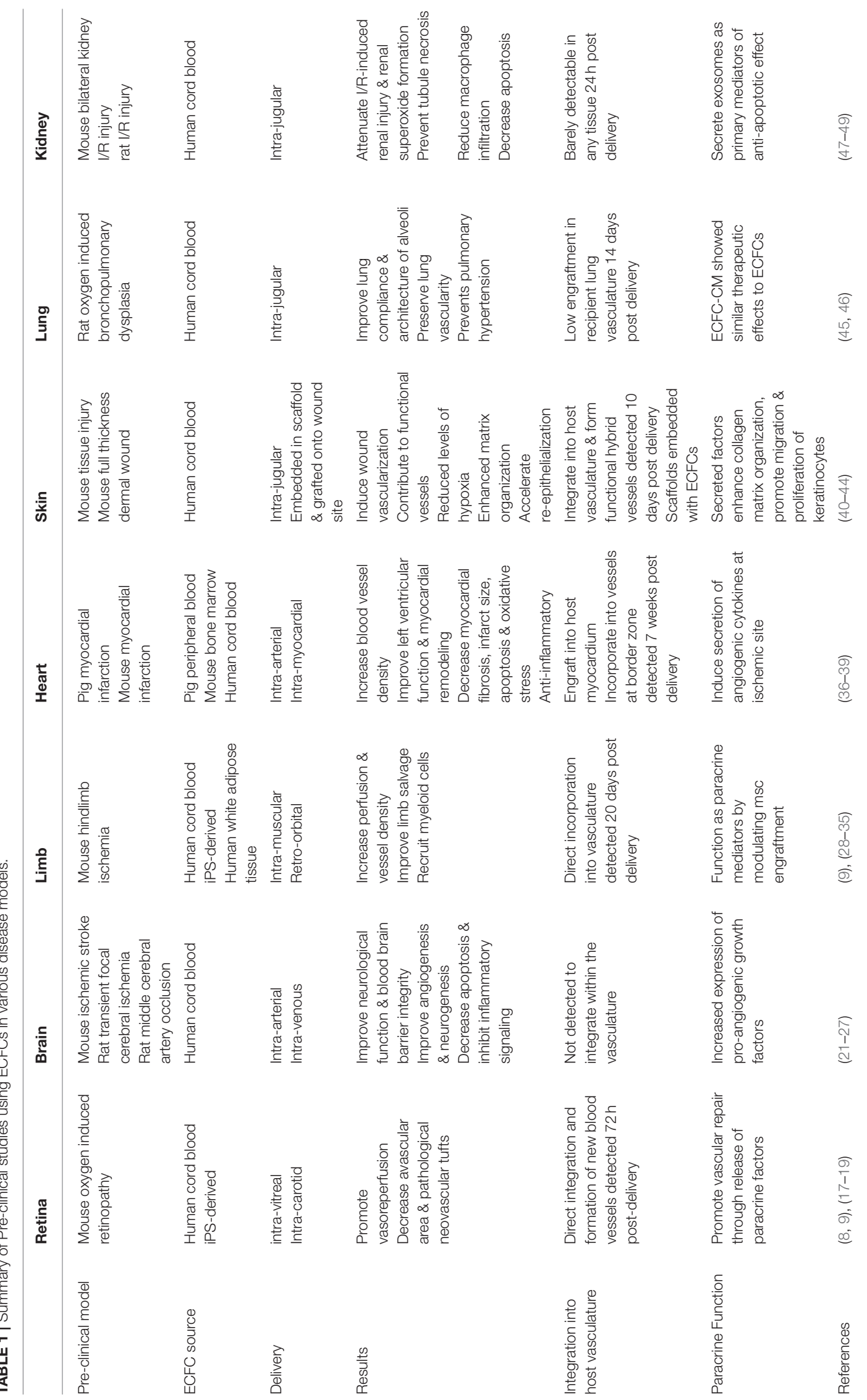


via PDGF-BB/PDGFRb signaling (29). Similar beneficial effects were reported in a later study in which ECFCs combined with mesenchymal progenitor cells enhanced blood flow recovery of the ischemic limb. Interestingly, analysis showed that improved blood flow was in part due to the recruitment of host myeloid cells with, presumably, concomitant release of pro-angiogenic growth factors (30). Another study combining ECFCs and MSCs, via retro-orbital delivery, demonstrated the homing ability of the cells and increased vessel density via an endoglin-dependent mechanism (31). Modification or pre-treatment of ECFCs has been shown to enhance their effects. For example, ECFCinduced functional recovery and limb salvage were markedly improved by Fucoidan pre-treatment, which protected the cells from replicative cellular senescence (32). Overexpression of integrin $\mathrm{B} 1$ was also reported to augment ECFC vasoreparative potential as it improved homing of the cells to the ischemic tissue, leading to improved perfusion in the ischemic limbs (33). Similarly, adiponectin pre-treatment has been demonstrated to increase ECFCs neovascularization capacity in a hind limb model in streptozotocin-induced hyperglycemic nu/nu mice (34). ARA290, an agonist of Erythropoietin has also been shown to enhance ECFC function by increasing the homing of these cells to the ischemic limb (35). In addition, ECFCs derived from human induced pluripotent stem cells (iPSCs) have also been shown to contribute to hind limb vascular repair. In a model of hindlimb femoral vessel removal in nude mice, hiPSC ECFCs were shown to improve blood perfusion and limb salvage as well as cord blood-derived ECFCs (9). This result is important as it means that it may be possible to generate patient specific hiPSCderived ECFCs for autologous treatment of vascular disease.

\section{The Ischemic Myocardium}

Ischemic heart disease is a common cause of mortality worldwide. Cell therapy to regenerate the ischemic heart is a rapidly emerging concept. Most clinical trials have used bone marrow mononucleated cells (MNCs). Although bone marrow MNCs have demonstrated some therapeutic efficacy for the ischemic myocardium (51), they remain a very heterogeneous population of cells and therefore it is difficult to decipher the individual contributions of cell populations responsible for the repair. In addition, bone marrow MNCs from patients with ischemic heart disease have been shown to have a reduced neovascularization capacity (52). ECFCs remain to be tested clinically in the ischemic myocardium. The first pre-clinical studies were performed using $\mathrm{CD} 34+$ cells with presumed endothelial precursor capacity. These cells increased vessel density within the infarct area and improved left ventricular function although whether these heterogeneous cells were acting as paracrine reservoirs or endothelial "building blocks" remains unknown (36). Further pre-clinical studies have shown that ECFC therapy is beneficial; cells participate in the vascular repair process and promote vascular recovery of the ischemic heart. In an acute myocardial infarction model in pigs, infusion of autologous ECFC-like cells improved myocardial remodeling; decreased infarct size, increased vessel density and ECFCs were seen to incorporate within vessels at the border zone (37). Myocardial injection of ECFCs expressing AKT/HO-1 into a murine myocardial infarction model demonstrated an increase in blood vessel density, a decrease in apoptotic cells at the infarct site, reduction in oxidative stress and pro inflammatory molecule $\mathrm{TNF} \alpha$ as well as an improvement in ejection fraction (38). More recently, the transplantation of ECFCs pre-treated with Genistein was shown to increase cellular proliferation at the ischemic sites, enhance neovascularization, decrease myocardial fibrosis, and improve cardiac function (39).

\section{Wound Healing}

The inability to efficiently repair wounds is a common feature of patients suffering with vascular disease. Due to their angiogenic potential, ECFCs have been examined for their capacity to aid vascular repair in several wound injury models. In a murine model where tissue injury was induced by dye laser, digital intravital microscopy revealed that human umbilical cord bloodderived ECFCs delivered via infusion through the jugular vein migrate to sites of injury and promote endothelial regeneration (40). Interestingly, this study found that recruitment of ECFCs was dependent on the presence of neutrophils at the site of injury via the binding of P-selectin glycoprotein ligand-1 (PSGL-1) (40). In a murine model of full thickness dermal wound in athymic nude mice, unlike HUVECs, treatment with ECFCs was shown to induce wound vascularization by direct integration with host vasculature, demonstrated by blood filled vasculature. Furthermore, cells were detectable up until day 10, wounds that received ECFCs showed reduced levels of hypoxia, enhanced matrix organization and accelerated epithelial coverage. Interestingly, the border of the ECFC treated wounds contained smooth muscle cells likely mobilized by the secretion of PIGF and PDGF-BB by the ECFCs. This study also demonstrated ECFCs pro-angiogenic potential by paracrine factors: ECFCs expressed higher levels of pro-angiogenic growth factors such as VEGF, PIGF, and Ang-1 compared to HUVECs; ECFC-conditioned medium (CM) significantly improved collagen matrix organization from human dermal fibroblast sheets; and ECFC-CM boosted keratinocyte migration and proliferation across the wound via secretion of KGF and HGF (41). ECFCs also have the potential to be embedded within scaffolds or skin substitutes (42) where they can vascularize the scaffolds alone or in combination with accessory cells, and following subcutaneous transplantation, can anastomose within the host vasculature enabling perfusion (43). Cord blood-derived ECFCs seeded in a RGD-g-PLLA biosynthetic scaffold (designed to promote survival and retention of the cells at the wound site) enhanced dermal wound neovascularization and labeled ECFCs were seen to be retained in the wound up to a week after transplantation (44).

\section{The Lungs}

The lungs are highly vascularized organs. Recent research indicates that lung microvascular endothelium is a rich source of resident ECFCs, which contribute to normal vascular homeostasis $(12,14)$. Studies investigating the effects of ECFCs in the lung have shown beneficial effects. For example, in a rat injury model of oxygen-induced bronchopulmonary dysplasia, a lung disease of prematurity, human cord blood-derived ECFCs were administered through the jugular vein. ECFCs significantly improved lung compliance and the architecture of the alveoli. 
It also showed that ECFC therapy improved lung angiogenesis and prevented pulmonary hypertension in hyperoxia-exposed newborn mice. Treatment with ECFC-CM showed similar therapeutic effects in such models of bronchopulmonary dysplasia $(45,46)$. Such studies highlight that ECFCs may provide vasoreparative effects through paracrine mechanisms, in addition to direct vascular engraftment.

\section{The Kidney}

Ischemia reperfusion injury is the main cause of acute kidney injury (AKI) which results in endothelial cell loss and apoptosis, leading to reduction in peritubular capillary blood flow (53). ECFCs may facilitate the development of new treatments for AKI. The administration of ECFCs in a mouse model of ischemic AKI was shown to reduce tubular injury, renal apoptosis, and infiltration of macrophages and attenuate increases in plasma creatinine levels. Because there was little evidence of ECFCs remaining within the murine kidneys, their protective effects were primarily attributed to the release of exosomes, as injecting ECFC-derived exosomes alone protected against the multiple parameters of kidney injury (47). A follow-up study showed that specifically the microRNA miR-486-5p, present at high amounts within the ECFC exosomes, accounted for the therapeutic effects of ECFCs (48). In agreement with this, other studies have also shown that ECFCs secrete soluble factors to preserve microvascular function. Conditioned media from human cord blood-derived ECFCs offered protection in a rat model of ischemia reperfusion injury. Interestingly, ECFC-CM significantly reduced ICAM-1 expression and decreased the number of differentiated lymphocytes recruited to the kidney after renal ischemia (49). These studies suggest that ECFCs and their CM may provide a therapeutic option for the treatment of AKI.

\section{FUTURE PERSPECTIVES}

The studies discussed in this review (Table 1), support the case for ECFCs as a potential novel endothelial cell therapy that promotes vascular repair in many different vascular beds albeit tissue specific endothelial heterogeneity. It is possible that ECFCs, as progenitors, have required plasticity to adopt organ specific endothelial characteristics. A sole mechanism of action (MOA) for ECFC beneficial effects remains unclear. In some of these studies, ECFCs facilitate vascular repair by directly integrating within the host vasculature, while in others vascular engraftment of these cells is low or completely absent and their therapeutic benefit can be explained by the paracrine release of proangiogenic growth factors. More research is needed to fully elucidate mechanisms of action, but these are likely to depend on the experimental model used. Demonstration of long-term engraftment in pre-clinical models is challenging considering ECFCs are human cells delivered into immunocompetent mice. Other factors that need to be considered for each target disease are cell dosage, delivery route, and timing of ECFC administration (1).

To induce maximal therapeutic efficacy, it may be worthwhile considering co-transplantation of ECFCs with accessory cells such as MSCs (28, 30), smooth muscle cells (SMCs) (54), adipose tissue-derived stem cells (43) or myeloid angiogenic cells (55). Several studies have shown this to be an effective approach as it may promote long-term neovascularization by directly supporting and stabilizing ECFC-derived neovessels and also by providing proangiogenic factors to aid the regenerative process.

The majority of studies described in this review have been performed using a xeno-allogenic approach, testing human cells in mouse and rat models. However, in order to translate this work toward the clinical setting; it might be necessary to collect data from larger animal models, which may also allow an autologous approach. ECFCs have successfully been isolated from rabbits (56), dogs (57), pigs (58), sheep (59), horses (60), and monkeys (61) and there is some evidence for autologous ECFC therapy to be efficacious in pigs (37). Despite these results, when considering the use of ECFCs as a potential cytotherapy for human disease, it is likely that initial ECFC therapy may be allogeneic due to the fact that ECFCs cannot always be obtained efficiently from adult peripheral blood and those isolated from patients may be dysfunctional and therefore not optimal for cell transplantation. Another consideration is that ECFCs in human blood are very rare, and numbers are reduced with disease (62), thus it may not be possible to isolate them from every patient. Furthermore, isolation, characterization and ex-vivo expansion of autologous ECFCs requires 4-6 weeks which is a limiting factor for diseases with a narrow therapeutic window. Therefore, we consider ECFC allogeneic therapy as the most feasible and practical strategy in which ECFCs will be HLA typed to match patients and will be stored in cell banks as an "off-the-shelf" cell therapy product.

There is quite a high failure rate in successful translation of regenerative medicine therapies to clinical use. This is mainly due to potential cell products not passing the regulatory requirements, clinical efficacy standards, and the high manufacturing cost (63). Successful translation in the EPC field has been mainly impaired due to the use of heterogeneous populations of non-endothelial cells such as BM-MNCs, which have led to conflicting results and discourage pursue of further clinical trials (64). High cell population heterogeneity and low purity characterized the first generation of cell therapies, but next generation cell therapies require a highly pure and well-defined cell therapy product for consistency. In the EPC field, a recently published consensus on EPC nomenclature recommended accurate cell definitions and meaningful nomenclature (7).

This review shows pre-clinical evidence suggesting that ECFCs have therapeutic value for ischemic diseases. Advances in cell therapy manufacture technologies in combination with a first-in-man clinical trial are needed to facilitate the translational pathway for ECFCs into patients. Importantly, both cells GMP manufacture and clinical trial design have to align with regulatory frameworks for advanced therapy medicinal products.

Finally, before ECFCs are used in the clinical setting, protocols for their isolation, culture, and expansion must strictly adhere to GMP standard operating procedures. GMP guidelines may vary from country to country (65). In addition, xeno-free culture conditions are preferable. Replacing the use of animal products 
required for ECFC culture, such as fetal bovine serum and rat Collagen I are being investigated by many groups. Strategies to overcome these issues include the use of human platelet lysate $(66,67)$ and the manufacture of GMP synthetic basement membrane substrates (68). In addition, the use of automated cell culture facilities will enable scalable and standardized methods to create a reliable and reproducible cell therapy product.

In conclusion, harnessing the reparative angiogenic capacity of ECFCs may provide an exciting new regenerative therapy for vascular disease, however there are still challenges to overcome, and more research is warranted before these can be used in the clinic.

\section{REFERENCES}

1. O’Neill CL, O’Doherty MT, Wilson SE, Rana AA, Hirst CE, Stitt AW, et al. Therapeutic revascularisation of ischemic tissue: the opportunities and challenges for therapy using vascular stem/progenitor cells. Stem Cell Res Ther. (2012) 3:31. doi: 10.1186/scrt122

2. Chen SL, Fang WW, Ye F, Liu YH, Qian J, Shan SJ, et al. Effect on left ventricular function of intracoronary transplantation of autologous bone marrow mesenchymal stem cell in patients with acute myocardial infarction. Am J Cardiol. (2004) 94:92-5. doi: 10.1016/j.amjcard.2004.03.034

3. Kane NM, Meloni M, Spencer HL, Craig MA, Strehl R, Milligan G, et al. Derivation of endothelial cells from human embryonic stem cells by directed differentiation: analysis of microRNA and angiogenesis in vitro and in vivo. Arterioscler Thromb Vasc Biol. (2010) 30:1389-97. doi: 10.1161/ATVBAHA.110.204800

4. Adams WJ, Zhang Y, Cloutier J, Kuchimanchi P, Newton G, Sehrawat $\mathrm{S}$, et al. Functional vascular endothelium derived from human induced pluripotent stem cells. Stem Cell Reports (2013) 1:105-13. doi: 10.1016/j.stemcr.2013.06.007

5. Ingram DA, Caplice NM, Yoder MC. Unresolved questions, changing definitions, and novel paradigms for defining endothelial progenitor cells. Blood (2005) 106:1525-31. doi: 10.1182/blood-2005-04-1509

6. Medina RJ, O’Neill CL, Sweeney M, Guduric-Fuchs J, Gardiner TA, Simpson DA, et al. Molecular analysis of endothelial progenitor cell (EPC) subtypes reveals two distinct cell populations with different identities. BMC Med Genomics (2010) 3:18. doi: 10.1186/1755-8794-3-18

7. Medina RJ, Barber CL, Sabatier F, Dignat-George F, Melero-Martin JM, Khosrotehrani $\mathrm{K}$, et al. Endothelial progenitors: a consensus statement on nomenclature. Stem Cells Transl Med. (2017) 6:1316-20. doi: $10.1002 /$ sctm.16-0360

8. Medina RJ, O’Neill CL, Humphreys MW, Gardiner TA, Stitt AW. Outgrowth endothelial cells: characterization and their potential for reversing ischemic retinopathy. Invest Ophthalmol Vis Sci. (2010) 51:5906-13. doi: 10.1167/iovs.09-4951

9. Prasain N, Lee MR, Vemula S, Meador JL, Yoshimoto M, Ferkowicz MJ, et al. Differentiation of human pluripotent stem cells to cells similar to cordblood endothelial colony-forming cells. Nat Biotechnol. (2014) 32:1151-7. doi: $10.1038 /$ nbt.3048

10. Lin RZ, Moreno-Luna R, Munoz-Hernandez R, Li D, Jaminet SC, Greene AK, et al. Human white adipose tissue vasculature contains endothelial colonyforming cells with robust in vivo vasculogenic potential. Angiogenesis (2013) 16:735-44. doi: 10.1007/s10456-013-9350-0

11. Patel J, Seppanen E, Chong MS, Yeo JS, Teo EY, Chan JK, et al. Prospective surface marker-based isolation and expansion of fetal endothelial colonyforming cells from human term placenta. Stem Cells Transl Med. (2013) 2:839-47. doi: 10.5966/sctm.2013-0092

12. Alphonse RS, Vadivel A, Zhong S, McConaghy S, Ohls R, Yoder MC, et al. The isolation and culture of endothelial colony-forming cells from human and rat lungs. Nat Protoc. (2015) 10:1697-708. doi: 10.1038/nprot.2015.107

\section{AUTHOR CONTRIBUTIONS}

CO and RM: conception and design; CO, RM, and AS: manuscript writing; KM, SC, and JG-F: final approval of manuscript; CO, RM, KM, and SC: figure and table design.

\section{FUNDING}

This work was supported by the Juvenile Diabetes Research Foundation, the Medical Research Council, the Leverhulme Trust, the National Eye Research Centre, Northern Ireland Health and Social Care R\&D Division, The Sir Jules Thorn Trust and Fight for Sight.
13. Yu QC, Song W, Wang D, Zeng YA. Identification of blood vascular endothelial stem cells by the expression of protein C receptor. Cell Res. (2016) 26:1079-98. doi: 10.1038/cr.2016.85

14. Wakabayashi T, Naito H, Suehiro JI, Lin Y, Kawaji H, Iba T, et al. CD157 marks tissue-resident endothelial stem cells with homeostatic and regenerative properties. Cell Stem Cell (2018) 22:384. doi: 10.1016/j.stem.2018. 01.010

15. Ingram DA, Mead LE, Tanaka H, Meade V, Fenoglio A, Mortell K, et al. Identification of a novel hierarchy of endothelial progenitor cells using human peripheral and umbilical cord blood. Blood (2004) 104:2752-60. doi: 10.1182/blood-2004-04-1396

16. Stitt AW, O’Neill CL, O’Doherty MT, Archer DB, Gardiner TA, Medina RJ. Vascular stem cells and ischemic retinopathies. Prog Retin Eye Res. (2011) 30:149-66. doi: 10.1016/j.preteyeres.2011.02.001

17. Reid E, Guduric-Fuchs J, O’Neill CL, Allen LD, Chambers SEJ, Stitt AW, et al. Preclinical evaluation and optimization of a cell therapy using human cord blood-derived endothelial colony-forming cells for ischemic retinopathies. Stem Cells Transl Med. (2018) 7:59-67. doi: 10.1002/sctm. 17-0187

18. Cahoon JM, Rai RR, Carroll LS, Uehara H, Zhang X, O'Neil CL, et al. Intravitreal AAV2.COMP-ang1 prevents neurovascular degeneration in a murine model of diabetic retinopathy. Diabetes (2015) 64:4247-59. doi: $10.2337 / \mathrm{db} 14-1030$

19. Sakimoto S, Marchetti V, Aguilar E, Lee K, Usui Y, Murinello S, et al. CD44 expression in endothelial colony-forming cells regulates neurovascular trophic effect. JCI Insight (2017) 2:e89906. doi: 10.1172/jci.insight.89906

20. Wardlaw JM, Sandercock PA, Murray V. Should more patients with acute ischemic stroke receive thrombolytic treatment? BMJ (2009) 339:b4584. doi: 10.1136/bmj.b4584

21. Ding J, Zhao Z, Wang C, Wang CX, Li PC, Qian C, et al. Bioluminescence imaging of transplanted human endothelial colony-forming cells in an ischemic mouse model. Brain Res. (2016) 1642:209-18. doi: 10.1016/j.brainres.2016.03.045

22. Pellegrini L, Bennis Y, Guillet B, Velly L, Garrigue P, Sabatier F, et al. Therapeutic benefit of a combined strategy using erythropoietin and endothelial progenitor cells after transient focal cerebral ischemia in rats. Neurol Res. (2013) 35:937-47. doi: 10.1179/1743132813Y.00000 00235

23. Garrigue P, Hache G, Bennis Y, Brige P, Stalin J, Pellegrini L, et al. Erythropoietin pretreatment of transplanted endothelial colony-forming cells enhances recovery in a cerebral ischemia model by increasing their homing ability: a SPECT/CT study. J Nucl Med. (2016) 57:1798-804. doi: 10.2967/jnumed.115.170308

24. Moubarik C, Guillet B, Youssef B, Codaccioni JL, Piercecchi MD, Sabatier F, et al. Transplanted late outgrowth endothelial progenitor cells as cell therapy product for stroke. Stem Cell Rev. (2011) 7:208-20. doi: 10.1007/s12015-010-9157-y

25. Zhang Y, Li Y, Wang S, Han Z, Huang X, Li S, et al. Transplantation of expanded endothelial colony-forming cells improved outcomes of 
traumatic brain injury in a mouse model. J Surg Res. (2013) 185:441-9. doi: $10.1016 /$ j.jss.2013.05.073

26. Huang XT, Zhang YQ, Li SJ, Li SH, Tang Q, Wang ZT, et al. Intracerebroventricular transplantation of ex vivo expanded endothelial colony-forming cells restores blood-brain barrier integrity and promotes angiogenesis of mice with traumatic brain injury. J Neurotrauma (2013) 30:2080-8. doi: 10.1089/neu.2013.2996

27. Li S, Tian Y, Huang X, Zhang Y, Wang D, Wei $\mathrm{H}$, et al. Intravenous transfusion of endothelial colony-forming cells attenuates vascular degeneration after cerebral aneurysm induction. Brain Res. (2014) 1593:65-75. doi: 10.1016/j.brainres.2014.09.077

28. Schwarz TM, Leicht SF, Radic T, Rodriguez-Arabaolaza I, Hermann PC, Berger F, et al. Vascular incorporation of endothelial colony-forming cells is essential for functional recovery of murine ischemic tissue following cell therapy. Arterioscler Thromb Vasc Biol. (2012) 32:e13-21. doi: 10.1161/ATVBAHA.111.239822

29. Lin RZ, Moreno-Luna R, Li D, Jaminet SC, Greene AK, Melero-Martin JM. Human endothelial colony-forming cells serve as trophic mediators for mesenchymal stem cell engraftment via paracrine signaling. Proc Natl Acad Sci USA. (2014) 111:10137-42. doi: 10.1073/pnas.1405388111

30. Kang KT, Lin RZ, Kuppermann D, Melero-Martin JM, Bischoff J. Endothelial colony forming cells and mesenchymal progenitor cells form blood vessels and increase blood flow in ischemic muscle. Sci Rep. (2017) 7:770. doi: 10.1038/s41598-017-00809-1

31. Rossi E, Smadja D, Goyard C, Cras A, Dizier B, Bacha N, et al. Co-injection of mesenchymal stem cells with endothelial progenitor cells accelerates muscle recovery in hind limb ischemia through an endoglin-dependent mechanism. Thromb Haemost (2017) 117:1908-18. doi: 10.1160/TH17-01-0007

32. Lee JH, Lee SH, Choi SH, Asahara T, Kwon SM. The sulfated polysaccharide fucoidan rescues senescence of endothelial colony-forming cells for ischemic repair. Stem Cells (2015) 33:1939-51. doi: 10.1002/stem.1973

33. Goto K, Takemura G, Takahashi T, Okada H, Kanamori H, Kawamura I, et al. Intravenous administration of endothelial colony-forming cells overexpressing integrin betal augments angiogenesis in ischemic legs. Stem Cells Transl Med. (2016) 5:218-26. doi: 10.5966/sctm.2015-0096

34. Leicht SF, Schwarz TM, Hermann PC, Seissler J, Aicher A, Heeschen C. Adiponectin pretreatment counteracts the detrimental effect of a diabetic environment on endothelial progenitors. Diabetes (2011) 60:652-61. doi: $10.2337 / \mathrm{db} 10-0240$

35. Hache G, Garrigue P, Bennis Y, Stalin J, Moyon A, Cerami A, et al. ARA290, a specific agonist of erythropoietin/CD131 heteroreceptor, improves circulating endothelial progenitors' angiogenic potential and homing ability. Shock (2016) 46:390-7. doi: 10.1097/SHK.0000000000000606

36. Kocher AA, Schuster MD, Szabolcs MJ, Takuma S, Burkhoff D, Wang J, et al. Neovascularization of ischemic myocardium by human bone-marrowderived angioblasts prevents cardiomyocyte apoptosis, reduces remodeling and improves cardiac function. Nat Med. (2001) 7:430-6. doi: 10.1038/86498

37. Dubois C, Liu X, Claus P, Marsboom G, Pokreisz P, Vandenwijngaert $S$, et al. Differential effects of progenitor cell populations on left ventricular remodeling and myocardial neovascularization after myocardial infarction. J Am Coll Cardiol. (2010) 55:2232-43. doi: 10.1016/j.jacc.2009. 10.081

38. Brunt KR, Wu J, Chen Z, Poeckel D, Dercho RA, Melo LG, et al. Ex vivo Akt/HO-1 gene therapy to human endothelial progenitor cells enhances myocardial infarction recovery. Cell Transpl. (2012) 21:1443-61. doi: 10.3727/096368912X653002

39. Lee SH, Lee JH, Asahara T, Kim YS, Jeong HC, Ahn Y, et al. Genistein promotes endothelial colony-forming cell (ECFC) bioactivities and cardiac regeneration in myocardial infarction. PLoS ONE (2014) 9:e96155. doi: 10.1371/journal.pone.0096155

40. Hubert L, Darbousset R, Panicot-Dubois L, Robert S, Sabatier F, Fallague K, et al. Neutrophils recruit and activate human endothelial colony-forming cells at the site of vessel injury via P-selectin glycoprotein ligand-1 and L-selectin. $J$ Thromb Haemost. (2014) 12:1170-81. doi: 10.1111/jth.12551

41. Hendrickx B, Verdonck K, Van den Berge S, Dickens S, Eriksson E, Vranckx JJ, et al. Integration of blood outgrowth endothelial cells in dermal fibroblast sheets promotes full thickness wound healing. Stem Cells (2010) 28:1165-77. doi: $10.1002 /$ stem.445
42. Athanassopoulos A, Tsaknakis G, Newey SE, Harris AL, Kean J, Tyler MP, et al. Microvessel networks [corrected] pre-formed in artificial clinical grade dermal substitutes in vitro using cells from haematopoietic tissues. Burns (2012) 38:691-701. doi: 10.1016/j.burns.2011.12.019

43. Traktuev DO, Prater DN, Merfeld-Clauss S, Sanjeevaiah AR, Saadatzadeh MR, Murphy M, et al. Robust functional vascular network formation in vivo by cooperation of adipose progenitor and endothelial cells. Circ Res. (2009) 104:1410-20. doi: 10.1161/CIRCRESAHA.108.190926

44. Kim KL, Han DK, Park K, Song SH, Kim JY, Kim JM, et al. Enhanced dermal wound neovascularization by targeted delivery of endothelial progenitor cells using an RGD-g-PLLA scaffold. Biomaterials (2009) 30:37428. doi: $10.1016 / \mathrm{j}$.biomaterials.2009.03.053

45. Alphonse RS, Vadivel A, Fung M, Shelley WC, Critser PJ, Ionescu L, et al. Existence, functional impairment, and lung repair potential of endothelial colony-forming cells in oxygen-induced arrested alveolar growth. Circulation (2014) 129:2144-57. doi: 10.1161/CIRCULATIONAHA.114.009124

46. Baker CD, Seedorf GJ, Wisniewski BL, Black CP, Ryan SL, Balasubramaniam $\mathrm{V}$, et al. Endothelial colony-forming cell conditioned media promote angiogenesis in vitro and prevent pulmonary hypertension in experimental bronchopulmonary dysplasia. Am J Physiol Lung Cell Mol Physiol. (2013) 305:L73-81. doi: 10.1152/ajplung.00400.2012

47. Burger D, Vinas JL, Akbari S, Dehak H, Knoll W, Gutsol A, et al. Human endothelial colony-forming cells protect against acute kidney injury: role of exosomes. Am J Pathol. (2015) 185:2309-23. doi: 10.1016/j.ajpath.2015.04.010

48. Vinas JL, Burger D, Zimpelmann J, Haneef R, Knoll W, Campbell P, et al. Transfer of microRNA-486-5p from human endothelial colony forming cellderived exosomes reduces ischemic kidney injury. Kidney Int. (2016) 90:123850. doi: 10.1016/j.kint.2016.07.015

49. Collett JA, Mehrotra P, Crone A, Shelley WC, Yoder MC, Basile DP. Endothelial colony-forming cells ameliorate endothelial dysfunction via secreted factors following ischemia-reperfusion injury. Am J Physiol Renal Physiol. (2017) 312:F897-907. doi: 10.1152/ajprenal.00643.2016

50. Morley RL, Sharma A, Horsch AD, Hinchliffe RJ. Peripheral artery disease. BMJ (2018) 360:j5842. doi: 10.1136/bmj.j5842

51. Moccetti T, Surder D, Klersy C, Vassalli G, Crljenica C, Rossi MG, et al. Sustained improvement in left ventricular function after bone marrow derived cell therapy in patients with acute ST elevation myocardial infarction. A 5year follow-up from the Stem Cell Transplantation in Ischemic Myocardium Study. Swiss Med Wkly (2012) 142:w13632. doi: 10.4414/smw.2012.13632

52. Heeschen C, Lehmann R, Honold J, Assmus B, Aicher A, Walter DH, et al. Profoundly reduced neovascularization capacity of bone marrow mononuclear cells derived from patients with chronic ischemic heart disease. Circulation (2004) 109:1615-22. doi: 10.1161/01.CIR.0000124476.32871.E3

53. Malek M, Nematbakhsh M. Renal ischemia/reperfusion injury; from pathophysiology to treatment. J Renal Inj Prev. (2015) 4:20-7. doi: 10.12861/jrip.2015.06

54. Melero-Martin JM, Khan ZA, Picard A, Wu X, Paruchuri S, Bischoff J. In vivo vasculogenic potential of human blood-derived endothelial progenitor cells. Blood (2007) 109:4761-8. doi: 10.1182/blood-2006-12-062471

55. O'Neill CL, Guduric-Fuchs J, Chambers SE, O’Doherty M, Bottazzi B, Stitt $\mathrm{AW}$, et al. Endothelial cell-derived pentraxin 3 limits the vasoreparative therapeutic potential of circulating angiogenic cells. Cardiovasc Res. (2016) 112:677-88. doi: $10.1093 / \mathrm{cvr} / \mathrm{cvw} 209$

56. Gulati R, Jevremovic D, Witt TA, Kleppe LS, Vile RG, Lerman A, et al. Modulation of the vascular response to injury by autologous blood-derived outgrowth endothelial cells. Am J Physiol Heart Circ Physiol. (2004) 287:H512-7. doi: 10.1152/ajpheart.00063.2004

57. He H, Shirota T, Yasui H, Matsuda T. Canine endothelial progenitor cell-lined hybrid vascular graft with nonthrombogenic potential. J Thorac Cardiovasc Surg. (2003) 126:455-64. doi: 10.1016/S0022-5223(02)73264-9

58. Huang L, Hou D, Thompson MA, Baysden SE, Shelley WC, Ingram DA, et al. Acute myocardial infarction in swine rapidly and selectively releases highly proliferative endothelial colony forming cells (ECFCs) into circulation. Cell Transplant (2007) 16:887-97.

59. Kaushal S, Amiel GE, Guleserian KJ, Shapira OM, Perry T, Sutherland FW, et al. Functional small-diameter neovessels created using endothelial progenitor cells expanded ex vivo. Nat Med. (2001) 7:1035-40. doi: $10.1038 / \mathrm{nm} 0901-1035$ 
60. Seeto WJ, Tian Y, Winter RL, Caldwell FJ, Wooldridge AA, Lipke EA. Encapsulation of equine endothelial colony forming cells in highly uniform, injectable hydrogel microspheres for local cell delivery. Tissue Eng Part C Methods (2017) 23:815-25. doi: 10.1089/ten.tec. 2017.0233

61. Shelley WC, Leapley AC, Huang L, Critser PJ, Zeng P, Prater D, et al. Changes in the frequency and in vivo vessel-forming ability of rhesus monkey circulating endothelial colony-forming cells across the lifespan (birth to aged). Pediatr Res. (2012) 71:156-61. doi: 10.1038/pr.2011.22

62. Ingram DA, Lien IZ, Mead LE, Estes M, Prater DN, Derr-Yellin E, et al. In vitro hyperglycemia or a diabetic intrauterine environment reduces neonatal endothelial colony-forming cell numbers and function. Diabetes (2008) 57:724-31. doi: $10.2337 / \mathrm{db} 07-1507$

63. Daley GQ. The promise and perils of stem cell therapeutics. Cell Stem Cell (2012) 10:740-9. doi: 10.1016/j.stem.2012.05.010

64. A futile cycle in cell therapy. Nat Biotechnol. (2017) 35:291. doi: $10.1038 /$ nbt.3857

65. Sheu J, Klassen H, Bauer G. Cellular manufacturing for clinical applications. Dev Ophthalmol. (2014) 53:178-88. doi: 10.1159/000357362

66. Kim H, Prasain N, Vemula S, Ferkowicz MJ, Yoshimoto M, Voytik-Harbin SL, et al. Human platelet lysate improves human cord blood derived ECFC survival and vasculogenesis in three dimensional (3D) collagen matrices. Microvasc Res (2015) 101:72-81. doi: 10.1016/j.mvr.2015.06.006

67. Siegel G, Fleck E, Elser S, Hermanutz-Klein U, Waidmann M, Northoff $\mathrm{H}$, et al. Manufacture of endothelial colony-forming progenitor cells from steady-state peripheral blood leukapheresis using pooled human platelet lysate. Transfusion (2018) 58:1132-42. doi: 10.1111/trf.14541

68. Hagbard L, Cameron K, August P, Penton C, Parmar M, Hay DC, et al. Developing defined substrates for stem cell culture and differentiation. Philos Trans R Soc Lond B Biol Sci (2018) 373:20170230. doi: 10.1098/rstb.2017.0230

Conflict of Interest Statement: The authors declare that the research was conducted in the absence of any commercial or financial relationships that could be construed as a potential conflict of interest.

Copyright (C) 2018 O'Neill, McLoughlin, Chambers, Guduric-Fuchs, Stitt and Medina. This is an open-access article distributed under the terms of the Creative Commons Attribution License (CC BY). The use, distribution or reproduction in other forums is permitted, provided the original author(s) and the copyright owner(s) are credited and that the original publication in this journal is cited, in accordance with accepted academic practice. No use, distribution or reproduction is permitted which does not comply with these terms. 